\title{
OBSERVATIONS ON AGGREGATIONS OF MALES OF TWO SPECIES OF BEEWOLVES \\ (HYMENOPTERA: SPHECIDAE: PHILANTHUS)
}

\author{
By HOWARD E. EVANS \\ Department of Entomology \\ Colorado State University \\ Fort Collins, CO 80523
}

\section{INTRODUCTION}

It is well known that populations of beewolves (Philanthus) may persist in suitable places for many years so long as there is no serious disturbance to the habitat (Evans and O'Neill 1988). Within these sites nest density may vary considerably, and the distribution of defended, scent-marked territories is closely dependent upon nest density. When nests are highly clumped, males establish territories apart from but adjacent to the nests, often in flyways used by the females (e.g. in P. pulcher). When nests are moderately spaced, males may establish territories among the nests (e.g. in $P$. bicinctus). When nests are widely dispersed, males aggregate to form leks, perhaps resulting in a more massive chemical signal that attracts females from a distance (e.g. in P. basilaris). Intraspecific variation in nest density and corresponding distribution of males has been reported for several species (Evans and O'Neill 1988).

This report concerns populations of two species in which the nests are widely dispersed and in which males aggregate each year at the same site and indeed occupy the same or very similar territorial spaces year after year. The two species, barbatus and crabroniformis, are members of the gibbosus group and are very similar in structure as well as in size and coloration. The two species are sympatric throughout much of the West and both occur at moderate elevations in montane areas. The present studies were conducted about $20 \mathrm{~km}$ west of Livermore, Larimer Co., Colorado, at elevations of 2130-2260 m. This is an area of rolling hills covered with grasses, forbs, bushes, and irregularly distributed ponderosa pines, Douglas-firs, and junipers. Patches of bare, friable soil suitable as

Manuscript received 6 January 1993. 
nesting sites are sparse, and females of both barbatus and crabroniformis have been found nesting only in scattered eroded slopes and in banks along gravel roads. $P$. crabroniformis emerges two to three weeks earlier than barbatus, but it is not unusual to find both sexes of both species feeding at Solidago blossoms in late summer. An aggregation of males of each species has now been monitored for 7-8 years. That of crabroniformis is located just below a hilltop, that of barbatus at the bottom of a broad gully $1.8 \mathrm{~km}$ away. Thus both are on fairly prominent landmarks, though of a very different nature.

McDaniel et al. (1992) have recently studied the territorymarking pheromones of these two species, basing their analyses on specimens taken from these same two populations. The pheromones were found to be very different, that of barbatus containing mainly aldehydes and the ester ethyl tetradecanoate, that of crabroniformis lacking aldehydes but containing several esters other than ethyl tetradecanoate. The pheromones of six species of Philanthus have now been analyzed by McDaniel and his associates, and all have been found to be quite different. In the present instance, the two species overlap only slightly in time and aggregate at quite different sites, but this may not be the case in other localities.

\section{Philanthus crabroniformis}

An assemblage of males has formed each of seven years (1986-1992) on the northeast side of a hill surmounted by a rocky outcrop, at an altitude of $2260 \mathrm{~m}$. Males have appeared each year about July 1 and remained active for about four weeks. Each occupied a territory roughly a meter in diameter on the ground beneath an open canopy of ponderosa pines, just a short distance below the top of the hill and somewhat shielded from the predominantly southwest summer winds. Perching occurred mainly on the ground, scent-marking on low grasses and forbs, mostly less than $0.5 \mathrm{~m}$ tall, or less commonly on low leaves of shrubs adjacent to territories, chiefly Cercocarpus and Juniperus. Males appeared each morning about 10 o'clock (Mountain Daylight Time) and remained active until mid-afternoon unless heavy clouds appeared. There was much aggression among males soon after they first appeared, and much scent-marking soon after they had established territories. 
Certain territories were occupied with great consistency. In 1989, 12 males were collected (for pheromone analysis) from only 4 territories; each was reoccupied within 4 to 43 minutes $(\overline{\mathrm{X}}=12.3$ min). One territory was reoccupied 4 times within 20 minutes as successive males were removed.

The overall area occupied by the aggregation measured 18 by $35 \mathrm{~m}$. Within that area three territorial spaces were occupied each of the seven years (Fig. 1). Others were occupied for several years, but not every year, still others during only one year. Those occupied over several years were also those most often occupied throughout the active season. For example, territory 12 (lowest solid circle in Fig. 1), occupied each of the seven years of study, was occupied in 1991 and 1992 on every day on which observations were made. At the other extreme, territory 20 (lowest hollow circle in Fig. 1) was seen to be occupied for only one day in 1991, and was not seen to have been occupied on other dates or other years. Other territories were intermediate in terms of yearly and daily occupation.

The area occupied by males was divided into two partially sunny parts by a grove of pines providing deep shade. An upper group of males occupied territories adjacent to the rocks, a lower group a grassy slope with scattered trees and bushes. In the upper group, during 1991, nearest neighbor distance between perches varied from 1.5 to $15 \mathrm{~m}(\overline{\mathrm{X}}=8.8 \mathrm{~m})$, while in the lower group nearest neighbor distance varied from 1.2 to $11 \mathrm{~m}(\overline{\mathrm{X}}=6.0 \mathrm{~m})$. About $15 \mathrm{~m}$ separated the closest territory from each group. The mean overall nearest neighbor distance was $9.7 \mathrm{~m}$.

These figures remained relatively constant from year to year during the major part of the active season (early and late in the season, when there were few territories, distances were greater). In the lower group, nearest neighbor distance averaged $6.5 \mathrm{~m}$ in 1988, 6.2 $\mathrm{m}$ in 1990 . The number of territorial males varied slightly from year to year. In 1988 I marked 16 territories, of which no more than 9 were occupied on any one day; in 1990 I marked 18 territories, of which no more than 10 were occupied on any one day; in 1991 I marked 20 territories, of which no more than 11 were occupied on any one day. In 1992 the population was low; only 7 territories were marked, of which no more than 4 were occupied on any one day. 


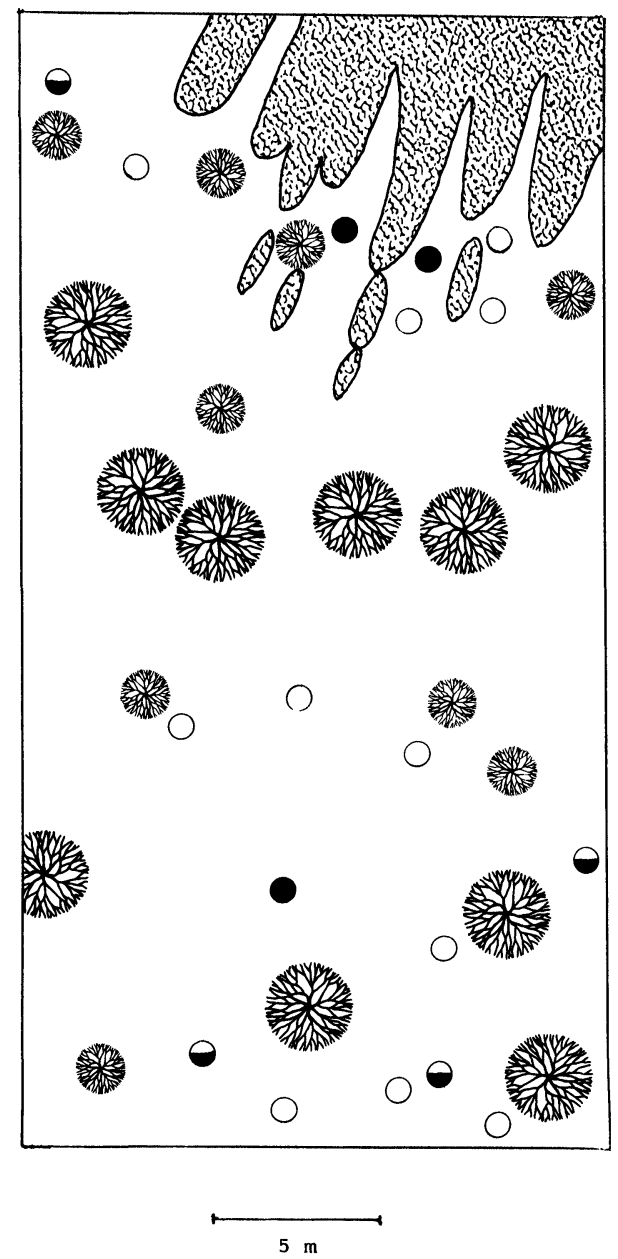

Fig. 1. Map of male territories of Philanthus crabroniformis. Sites occupied each year, 1986-1992, are shown as solid circles; sites occupied for at least 3 of the 7 years are shown as half-shaded circles; some of the sites occupied only one year are shown as hollow circles. A rocky outcrop at the top of the hill is shaded; trees and shrubs are shown by appropriate symbols. 
Careful search in surrounding areas failed to reveal further aggregations of males or any nests of females. The nearest nest was found in a sloping bank along a dirt road $2.2 \mathrm{~km}$ away. It seems likely that nests were scattered about over a wide area, in limited sites where there was a friable soil in eroded banks. This stands in contrast to a dense nesting aggregation of this species reported by Evans and O'Neill (1988) from Teton Co., Wyoming. In that case male territories were grouped a short distance upwind of the nests. In the present instance, it appeared that females were attracted from a wide area to a particular landmark where males had established territories and possibly produced enough pheromone to attract females from a distance. On no occasion did I observe females within the aggregation of males, but evidence from this and other species of Philanthus suggests that most mating occurs at male territories (Evans and O'Neill, 1988).

\section{Philanthus barbatus}

The aggregation of $P$. barbatus males was located $1.8 \mathrm{~km} \mathrm{SW}$ of the crabroniformis site, at an elevation of $2130 \mathrm{~m}$. Males occupied territories for each of eight years (1985-1992) at the bottom of a broad, generally dry ravine, in places that were sunny during much of the day, though shaded by nearby trees during the early morning and late afternoon. Males appeared each year in late July and remained active into early September. Thus there was limited overlap with crabroniformis in time (about a week), but the two aggregations were widely separated and located in very different topography.

Males arrived on territories each morning about 10:30 (MDT) and remained active until mid-afternoon unless there were heavy clouds. Territories were distributed in a somewhat linear pattern over an area about $20 \mathrm{~m}$ wide by $50 \mathrm{~m}$ long (Fig. 2). A gravel road and a ditch bisected the area; together these measured about $10 \mathrm{~m}$ across. Thus, as in the case of crabroniformis, there was a lower group of territories (no more than 3) and an upper group (of up to 12). Both sites were covered with tall grasses, $0.3-0.8 \mathrm{~m}$ high. Males selected perches among the grasses, usually on or close to the ground where there was bare soil or grasses that had been matted by the feet of mule deer or humans. Scent-marking occurred on the stems or tops of these grasses over a radius of as much as a 


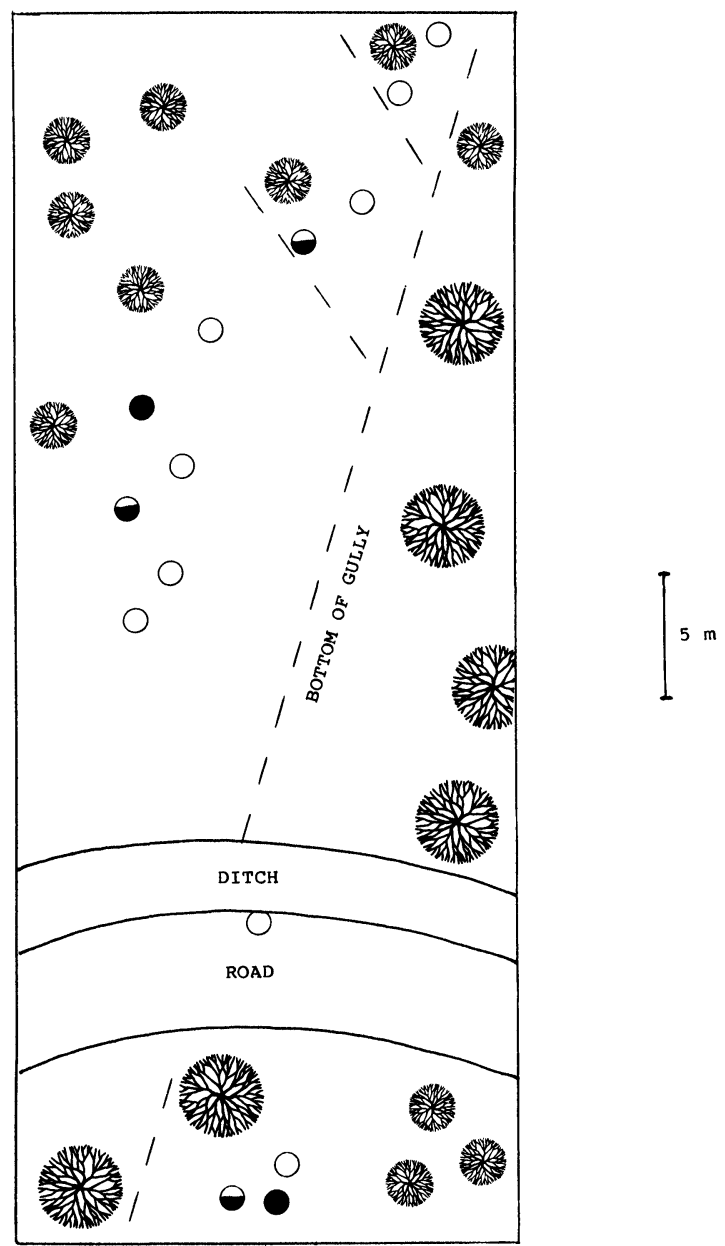

Fig. 2. Map of male territories of Philanthus barbatus. Sites occupied each year, 1985-1992, are shown as solid circles; sites occupied for at least 3 of the 8 years are shown as half-shaded circles; some of the sites occupied only one year are shown as hollow circles. Trees and shrubs are shown by appropriate symbols. 
meter from the perches. In the morning hours, much aggression occurred between males, including swirling flights and some butting and grappling. Evans and O'Neill (1988) reported briefly on the behavior of males at this site, based on observations made in 1985.

During 1988, 13 males were collected from as many territories on July 24 for pheromone studies. On the following day 13 more were collected, most of them from the same territories as the day before. Most of these same territorial spaces were found to be reoccupied on August 10. Two of these territorial spaces have been reoccupied each of the eight years, and it is these that are occupied most consistently throughout the season each year.

The number of territories varied from 6 to 13 over the period of study. During 1991, there were two territories in the lower group, the perches $2.5 \mathrm{~m}$ apart; in the upper group there were 11 territories, no more than 9 occupied on any one day. Nearest neighbor distance in the upper group varied from 1.6 to $8.3 \mathrm{~m}(\overline{\mathrm{X}}=5.5 \mathrm{~m})$.

Many hours of searching in the area revealed only one nest of a female, this in a bank along a dirt road about $0.3 \mathrm{~km}$ away. Other nests have been found on eroded banks at a distance of one to several $\mathrm{km}$ from the aggregation of males.

\section{DISCUSSION}

This area, covered as it is with open pine forests and with fields of diverse grasses, forbs, and bushes, offered few places where there was bare, friable soil suitable for nesting. Thus nests were scattered widely in banks along roads and in eroded slopes. Despite much effort, only a few nests of either species could be found, and these were widely separated from one another. This contrasts to other known populations of these same two species. Evans and O'Neill (1988) reported a dense aggregation of 16 nests of crabroniformis in a sandy track in Teton Co., Wyoming; males were grouped 1-8 $\mathrm{m}$ apart 40-60 $\mathrm{m}$ upwind of the nests. They also reported a group of 9 nests of barbatus in Larimer Co., Colorado, where there were territorial males only a few meters away.

The two populations considered here provide further examples of the persistence of male aggregations and of intraspecific variation in male mating tactics. When only widely dispersed nesting sites are available, it is evidently adaptive for males to seek 
communal territorial sites at conspicuous landmarks and for females to seek these landmarks either visually or in response to a more massive output of pheromone by males. It is curious that males of crabroniformis seek a slope adjacent to a rocky hilltop while those of the closely related barbatus establish their territories at the bottom of a ravine. It is perhaps worthy of note that the population of barbatus studied by Evans (1982) also occurred near the bottom of a ravine, though in this case territories and nests were only a few meters apart.

It is equally difficult to explain why certain territorial spaces are occupied each year. The pheromones applied to vegetation are not long persistent, and in any case the grass blades, stems, and leaves that are marked are not present year to year. It seems probable that males orient visually both to the territorial area and to specific points within it. Possibly they respond to cues provided by wind speed, overhead incidence of sunlight, and peripheral images of trees, shrubs, or rocks. A more or less bare space surrounded by vegetation is obviously required, but there were many such spaces in both areas that were not or only rarely occupied.

More or less permanent lekking sites are, of course, well known in some birds and mammals, and are especially well studied in grouse (Bergerud and Gratson, 1988). In most cases males move to traditional sites at mating season and attempt to gain central positions in the leks. The most favored territories of the two species of Philanthus considered here were not central in position. O'Neill (1983) found no evidence that larger (thus more dominant) males of $P$. basilaris occupied central positions in the leks. Evidently territory quality is determined by some factor other than a central position. If indeed females are attracted to pheromones from a distance, peripheral territories may be more likely to intercept females than central ones. Further study may add to our understanding of these matters.

\section{SUMMARY}

Populations of two species of beewolves were studied in montane areas in Larimer Co., Colorado. Males of each species have aggregated each of 7-8 years, either near the top of a hill (Philanthus crabroniformis) or near the bottom of a ravine (P. barbatus). In both cases there were certain territorial spaces that have been 
occupied each year of study, and these same spaces have also been occupied on each day of study throughout the season. Nests are widely dispersed, and females appear to be attracted to male aggregations with respect to landmarks and/or in response to the collective pheromones produced by the males. Why these sites are occupied each year, and why specific territorial spaces are reoccupied each year, remain to be explained.

\section{REFERENCES}

Bergerud, A. T. and M. W. Gratson, Editors

1988. Adaptive Strategies and Population Ecology of Northern Grouse. Minneapolis: Univ. Minnesota Press. 809 pp.

Evans, H. E.

1982. Nesting and territorial behavior of Philanthus barbatus Smith (Hymenoptera: Sphecidae). J. Kansas Entomol. Soc. 55: 571-576.

Evans, H. E. AND K. M. O’NEILl

1988. The Natural History and Behavior of North American Beewolves. Ithaca, N. Y.: Cornell Univ. Press. 278 pp.

MCDaniel, C. A., J. O. Schmidt, AND R. W. HowARD

1992. Mandibular gland secretions of the male beewolves Philanthus crabroniformis, $P$. barbatus, and $P$. pulcher (Hymenoptera: Sphecidae). J. Chem. Ecol. 18: 27-37.

O’NEILL, K. M.

1983. Territoriality, body size, and spacing in males of the beewolf Philanthus basilaris (Hymenoptera: Sphecidae). Behaviour 86: 295-321. 

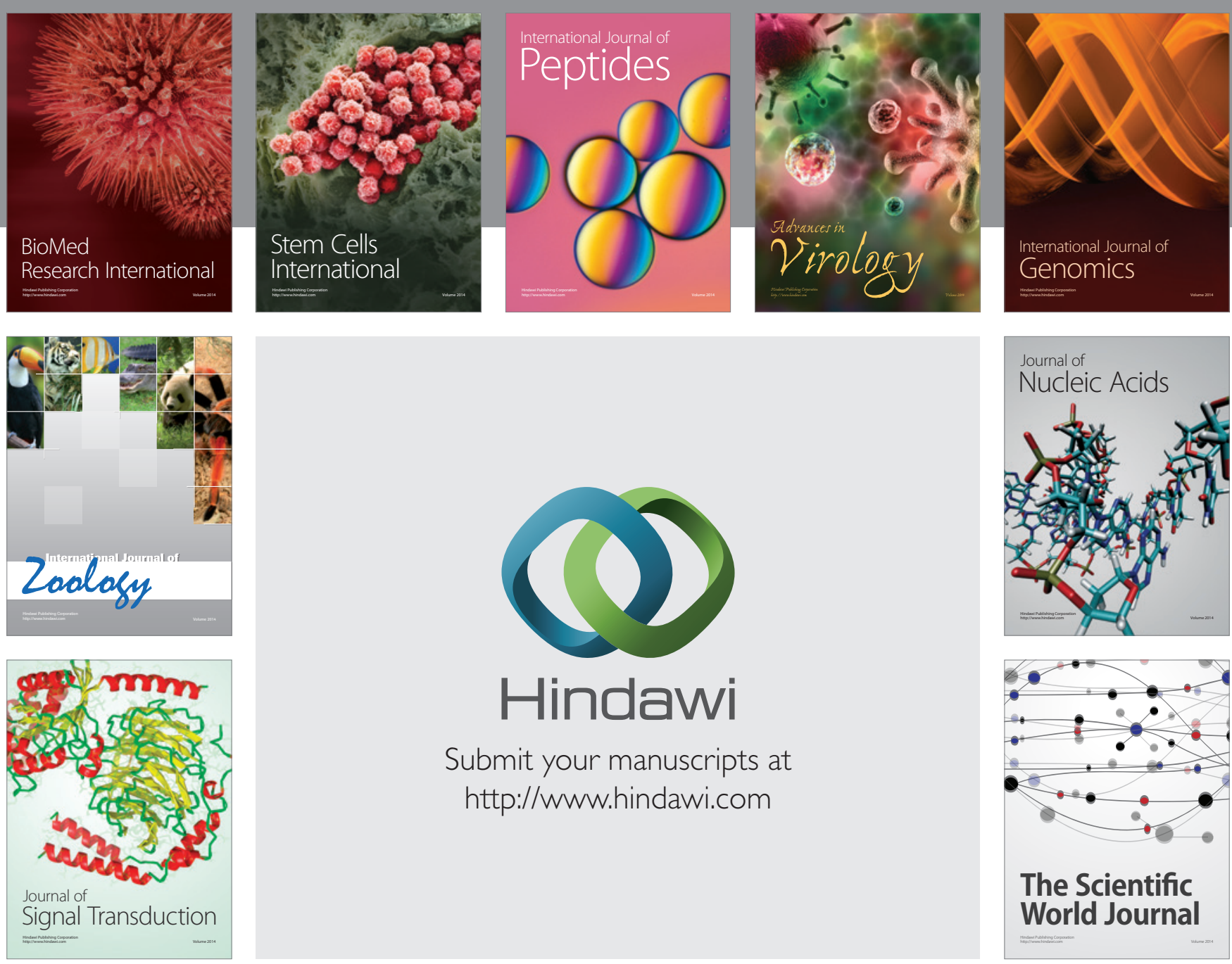

Submit your manuscripts at

http://www.hindawi.com
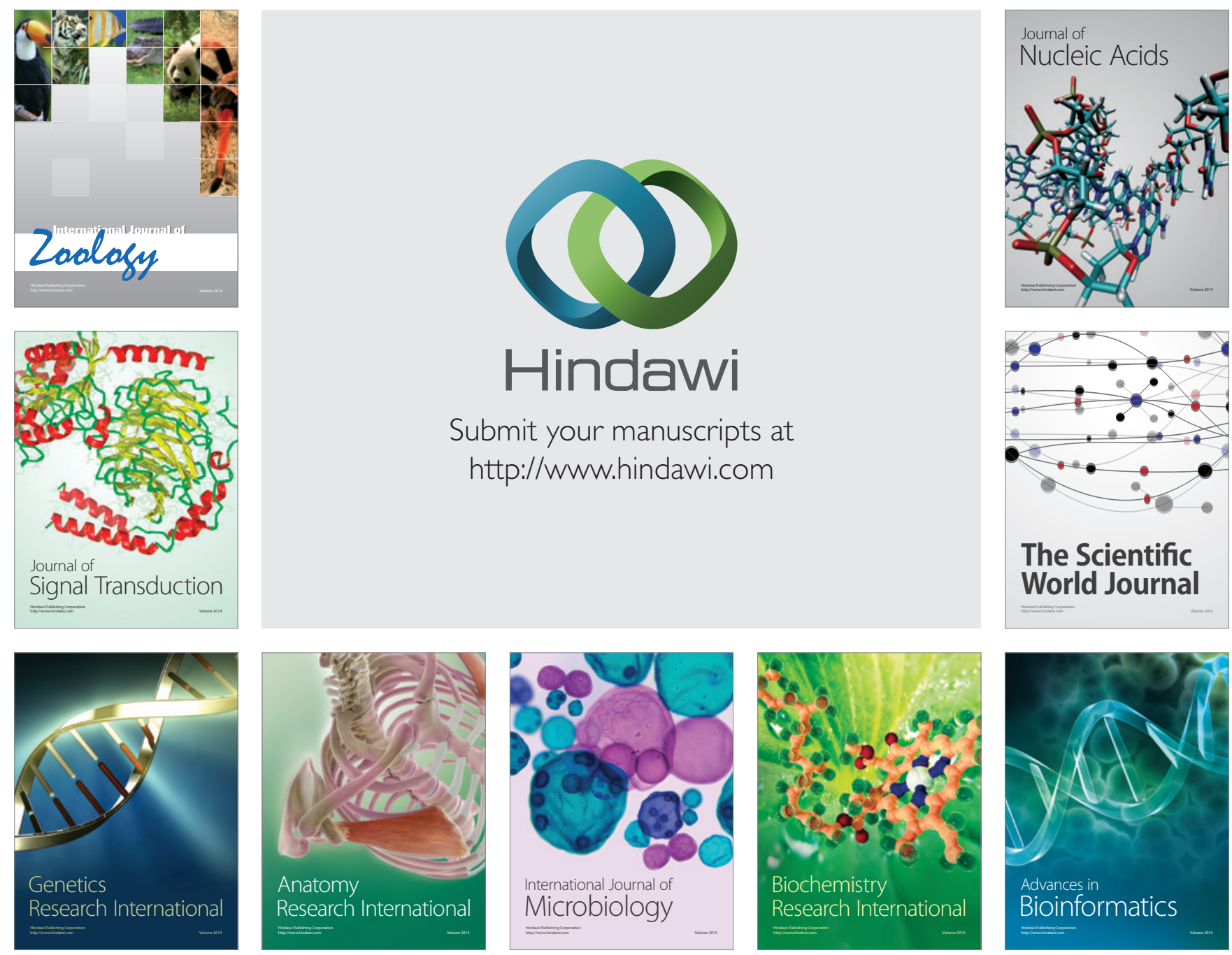

The Scientific World Journal
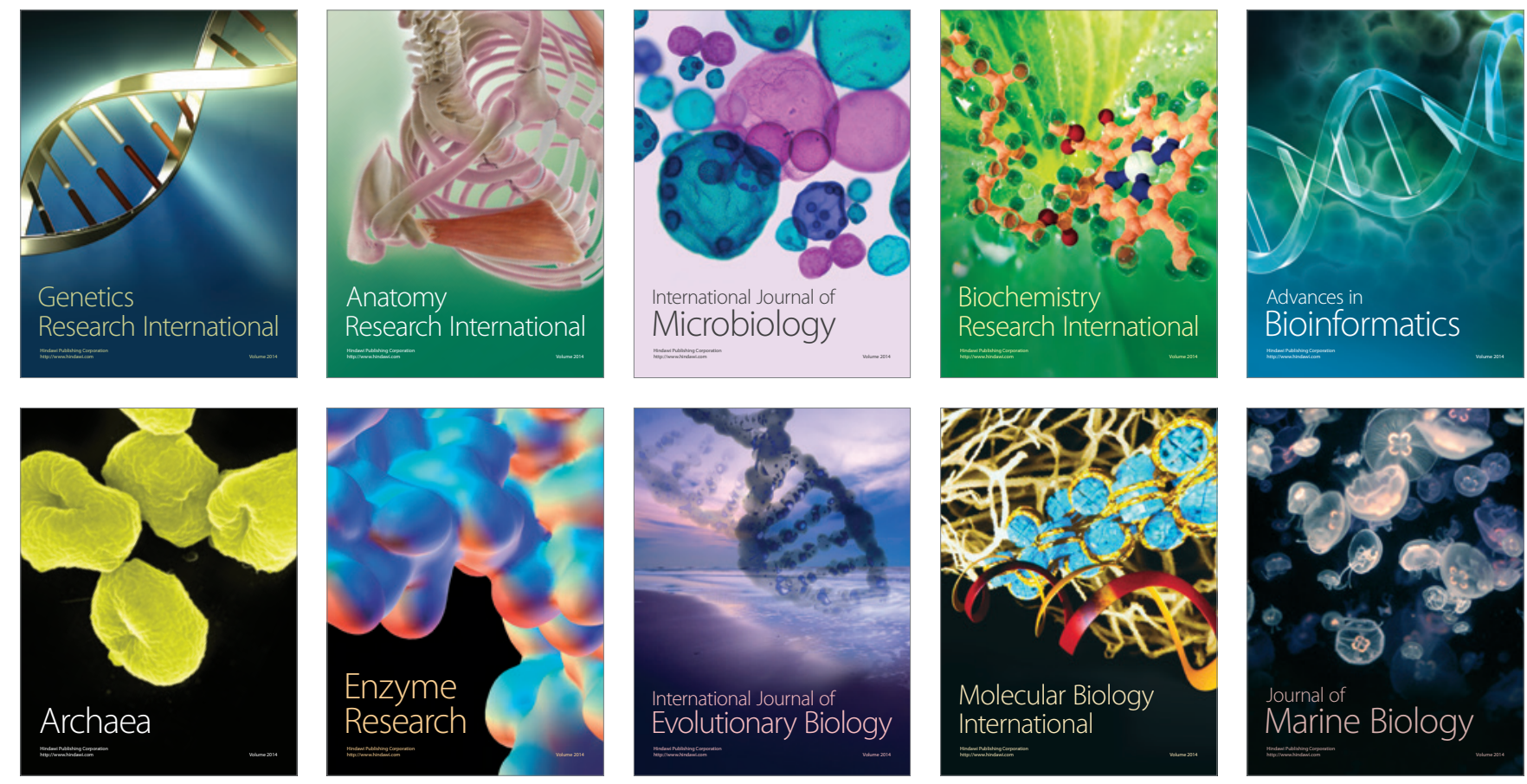